\title{
Analysis of different components in the peritumoral tissue microenvironment of colorectal cancer: A potential prospect in tumorigenesis
}

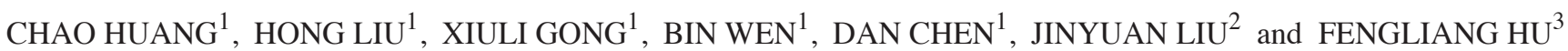 \\ ${ }^{1}$ Spleen-Stomach Institute; ${ }^{2}$ Pathology Department, Guangzhou University of Chinese Medicine; \\ ${ }^{3}$ The First Affiliated Hospital of Guangzhou University of Chinese Medicine, \\ Guangzhou, Guangdong 510000, P.R. China
}

Received July 29, 2015; Accepted June 2, 2016

DOI: $10.3892 / \mathrm{mmr} .2016 .5584$

\begin{abstract}
The present study aimed to observe the varying expression of biomarkers in the microenvironment adjacent to colorectal cancer lesions to provide additional insight into the functions of microenvironment components in carcinogenesis and present a novel or improved indicator for early diagnosis of cancer. A total of 144 human samples from three different locations in 48 patients were collected, these locations were 10,5 and $2 \mathrm{~cm}$ from the colorectal cancer lesion, respectively. The biomarkers analyzed included E-cadherin, cytokeratin 18 (CK18), hyaluronidase-1 (Hyal-1), collagen type I (Col-I), Crumbs3 (CRB3), vimentin, proteinase activated receptor 3 (PAR-3), $\alpha$-smooth muscle actin ( $\alpha$-SMA), cyclin D1 (CD1) and cluster of differentiation (CD)133. In addition, crypt architecture was observed. Related functional analysis of proteins was performed using hierarchical index cluster analysis. More severe destroyed crypt architecture closer to the cancer lesions was observed compared with the $10 \mathrm{~cm}$ sites, with certain crypts degraded entirely. Expression levels of E-cadherin, CK18, CRB3 and PAR-3 were lower in $2 \mathrm{~cm}$ sites compared with the $10 \mathrm{~cm}$ sites (all $\mathrm{P}<0.001$ ), while the expression levels of the other biomarkers in the $2 \mathrm{~cm}$ sites were increased compared with $10 \mathrm{~cm}$ sites (all $\mathrm{P}<0.0001$ ). Notably, the expression of CK18 in $2 \mathrm{~cm}$ sites was higher than in the $5 \mathrm{~cm}$ site $(\mathrm{P}<0.0001)$, which was different from the expression of E-cadherin, CRB3 and PAR-3. The expression levels of Hyal-1 and Col-I at the $2 \mathrm{~cm}$ sites were lower than that of the $5 \mathrm{~cm}$ sites $(\mathrm{P}>0.05$ and $\mathrm{P}=0.0001$, respectively), while the expression of vimentin, $\alpha$-SMA, CD1 and CD133 were not. Hyal-1 and Col-I may be independently important in cancer
\end{abstract}

Correspondence to: Mr. Chao Huang, Spleen-Stomach Institute, Guangzhou University of Chinese Medicine, 12 Airport Road, Guangzhou, Guangdong 510000, P.R. China

E-mail: huangchao06@163.com

Key words: colorectal cancer, tumor microenvironment, biomarker, carcinogenesis initiation in the tumor microenvironment. The results of the present study suggest that the biomarkers in the tissue microenvironment are associated with early tumorigenesis and may contribute to the development of carcinomas. These observations may be useful for early diagnosis of colorectal cancer.

\section{Introduction}

Somatic mutations have been demonstrated to be major factors in cancer development and progress, resulting in cell proliferation, tissue invasion, and an increased risk of metastasis (1). Increasing evidence indicates that the behavior of tumor cells is also influenced by their surrounding microenvironment, thus, a theory first presented in 1889, the 'seed and soil' hypothesis, has refreshed the view of tumorigenesis (2). Tumors have been demonstrated to be organ-like structures composed of various cell types whose interactions are crucial for driving and promoting tumor development and progression (3). As evidenced in the early literature, an aberrant microenvironment contributes to tumor initiation (4). Solid tumors are in synergy with their surrounding microenvironment to promote tumor growth and metastasis. Thus, targeting tumor cells and components in the microenvironment may provide a more effective method of early diagnosis and prevention of cancer. Improved understanding of the cancer microenvironment and its components allows further elucidation of the mechanisms underlying carcinogenesis in a novel.

Regulation of normal physiological processes during development of tumors may be destroyed and normal structures of cells, including apical-basal polarity, are lost (5). It is well known that cell polarity is vital to tissue homeostasis, thus, lost normal cell polarity promotes the initiation and progression of multiple cancer types (5). Common markers of polarity include E-cadherin (6), Crumbs3 (CRB3) $(7,8)$ and proteinase activated receptor 3 (PAR-3) (8), they function in tumorigenesis and cell migration and these markers were detected in the current study.

Cancer cells develop and progress in an aberrant microenvironment that favors growth and progression, and changes in the extracellular matrix (ECM) are one of numerous components that contribute to carcinogenesis (9). Abnormal 
tumor microenvironment (TME) consists of aberrant ECM components, including collagens, hyaluronic acid, and various cells, including fibroblasts, myofibroblasts, macrophages, lymphocytes and endothelial cells, these components are key in the initiation and progression of cancer (10-13). The ECM comprises a variety of proteins that contribute to the stability of tissue structure and physiological functions. Collagen type I (Col-I) is a major ECM protein (14), thus, it was selected to be investigated in order to elucidate the role of the ECM in cancer development. The current study also examined the expression levels of hyaluronidase-1 (Hyal-1), a major tumor-derived hyaluronidase (15). Dysregulation of different ECM components may favor the neoplastic process (16). Various cells, belonging to the ECM, are also important in tumor initiation and progression. $\alpha$-Smooth muscle actin ( $\alpha$-SMA) is a common marker for myofibroblasts (17) and cyclin D1 (CD1) is considered to be an oncogenic marker in a number of types of human cancer (18). Cluster of differentiation (CD)133 is a marker for adult stem cells in various types of tissue and tumors (19). Vimentin is an intermediate filament of mesenchymal tissue (20), and, similarly to cytokeratins (CKs), are markers of epithelial cells or epithelial cancer (21). These markers were investigated in the present study in order to analyze the importance of different cell types and proteins in the ECM on carcinogenesis.

The current study analyzed the expression levels of different components in the tissue microenvironment adjacent to colorectal cancer (CRC) lesions using immunohistochemistry (IHC) to investigation their association with early tumorigenesis. IHC, which is widely used in clinical cancer diagnostics, can preserve the morphology of tissue structures and demonstrate protein expression in various cell populations of complex tissues. For analysis of the process of cancer development, samples of different distances from the CRC lesion were collected.

\section{Materials and methods}

Sample collection. A total of 48 patients (age range, 49-73 years old) undergoing colonoscopic polypectomy in The First Affiliated Hospital of Guangzhou University of TCM (Guangzhou, China) between September 2013 and October 2014 were enrolled in the present study. Patients who had undergone neoadjuvant chemotherapy or radiotherapy were excluded from the study. Samples were collected from three different sites from each patient, and termed No. 1, No. 2 and No. 3, which were $\geq 10 \mathrm{~cm}, 5 \mathrm{~cm}$ and $\leq 2 \mathrm{~cm}$ distance from the proximal lesion of CRC tissue, respectively (Fig. 1). A total of 144 samples were collected. Informed consent was obtained from all participants and the present study was approved by the Institutional Ethics Committee of Guangzhou University of Chinese Medicine. The current study was performed in accordance with the ethical guidelines of the Declaration of Helsinki.

Hematoxylin and eosin staining of colonic crypts. The collected tissues were fixed with $4 \%$ paraformaldehyde, and then paraffin-embedded samples were cut into $4-\mu \mathrm{m}$ sections. After $10 \mathrm{~min}$ and $3 \mathrm{~min}$ treatments with dimethylbenzene and ethanol, respectively, the sections were stained with hematoxylin for $10 \mathrm{~min}$, and subsequently with $0.5 \%$ eosin for $3 \mathrm{~min}$, and then again treated with ethanol. The sections were sealed with neutral gum and observed for obtaining images with an inverted phase contrast microscope (Olympus).

IHC staining. The primary antibodies used in the IHC staining in the present study were as follows: Rabbit polyclonal against E-cadherin (Abcam, Cambridge, MA, USA; cat. no. ab15148), rat monoclonal against CRB3 (Abcam; cat. no. ab180835), rabbit monoclonal against $\alpha$-SMA (Abcam; cat. no. 124964), rabbit polyclonal against PAR-3 (Bioss, Inc., Woburn, MA, USA; cat. no. bs-9510R), rabbit polyclonal against Hyal-1 (Abcam; cat. no. ab103977), mouse monoclonal against Col-I (Abcam; cat. no. ab6308), rabbit polyclonal against cytokeratin 18 (CK18; Bioss, Inc.; cat. no. bs-1339R), rabbit polyclonal against vimentin (Bioss, Inc.; cat. no. bs-8533R), rabbit polyclonal against CD1 (Bioss, Inc.; cat. no. bs-0623R) and rabbit polyclonal against CD133 (Bioss, Inc.; cat. no. bs-0395R). Biotin-conjugated goat anti-rabbit (Wuhan Boster Biological Technology, Ltd., Wuhan, China; cat. no. SA1022), horseradish peroxidase-conjugated goat anti-mouse (Wuhan Boster Biological Technology, Ltd.; cat. no. BA1051) and anti-rat (Wuhan Boster Biological Technology, Ltd.; cat. no. SA1025) secondary antibodies were used.

All the biomarkers in the tissue samples were detected using IHC. Specimens were confirmed by hematoxylin and eosin staining of the sections. Formalin-fixed, paraffin-embedded sections $(4-\mu \mathrm{m})$ were deparaffinized in xylene, rehydrated in graded alcohol and rinsed in phosphate-buffered saline (PBS). Endogenous peroxidase activity was blocked with 3\% hydrogen peroxide in methanol for $20 \mathrm{~min}$. Epitope retrieval was performed in citrate buffer for $5 \mathrm{~min}$ at $100^{\circ} \mathrm{C}$. Slides were blocked in 5\% bovine serum albumin (Sigma-Aldrich, St. Louis, MO, USA) for $2 \mathrm{~h}$ at $37^{\circ} \mathrm{C}$. Slides were incubated with the primary antibodies $(1: 100)$ at $4^{\circ} \mathrm{C}$ overnight, washed with PBS $0.05 \%$ Tween 20 , and then incubated with secondary antibodies $(1: 1,000)$ at $37^{\circ} \mathrm{C}$ for $30 \mathrm{~min}$, prior to staining with diaminobenzidine, counterstaining with hematoxylin, dehydrated, coverslipped and then imaged using an inverted phase contrast microscope.

For immunostaining intensity, the staining was scored by two pathologists from 0 to 3 ( 0 , negative; 1 , weak staining; 2 , moderate staining; and 3, strong staining). The percentage of reactivity area was scored as follows: $1,<25 \% ; 2,25-50 \% ; 3$, $51-75 \%$ and $4,>75 \%$. Immunoreactive score was calculated by multiplying the scores of intensity and the scores of reactivity area. Immunoreactive score was classified into four degrees: Negative, 0 , weak, $1-4$, moderate, $6-8$, and strong, 9-12. The reactivity of all the markers was evaluated using an immunoreactive score.

PBS was used in place of the primary antibodies in each sample to serve as a negative control. Pathology image analysis software, IPP 6.0 (Media Cybernetics, Inc., Rockville, MD, USA), was applied to detect absorbance value (A) of the immune-positive product in each group. A total of six fields from each slide were randomly measured using value $\mathrm{A}$ of the same slide as a standard in order to obtain the corrected A (CCA) value of the sample. This was obtained subtracting the A value of the standard from the A value of the immunoreaction product producing the real optical density of the positive reaction, and the mean of six fields served as the mean 
CCA value of each sample. To avoid unnecessary error due to non-specific staining, data analysis and comparison was conducted using the mean CCA value. These data were used to perform related functional analysis using hierarchical index cluster, as described previously by with Knösel et al (22), using GenePix Pro software (version 6.0; Molecular Devices, LLC, Sunnyvale, CA, USA).

Statistical analysis. All data were analyzed using Stata 12.0 (StataCorp LP, College Station, TX, USA) software. The CCA values are presented as the mean \pm standard deviation. One-way analysis of variance was conducted to accomplish the comparison among the three groups, assuming that the data were normally distributed, with post-hoc least significance difference test. Non-parametric rank sum tests were performed when data were not normally distributed. $\mathrm{P}<0.05$ was considered to indicate a statistically significant difference.

\section{Results}

Observation of crypt structures demonstrated the degradation of normal colonic crypt architecture. Colonic crypts are stereotypical structures containing distinct stem cell proliferating, and stem cell differentiating compartments (23). Generally, although CRC derives from colonic crypt epithelia, it exhibits morphologically disarrayed glands (24). Thus, aberrant crypt foci (ACF) may be an early indicator of colon cancer development (25). The size and number of ACF is considered to be associated with CRC development.

In the current study, the crypts were vertically cut to observe histopathological characteristics of normal colon crypts (Fig. 2). The results indicated that the colon crypts without branching or protuberances presented a test-tube shape and smooth in surface (stained with hematoxylin and eosin; Fig. 2-A1). The crypt structures in sample No. 2 were larger than in sample No. 1. Compared with sample No. 1, the shape of crypts in sample No. 2 were lost (Fig. 2-A2), which is consistent with previous data demonstrating marked discrepancies from normal colonic crypt architecture (23).

Expression of biomarkers in tissue microenvironment differed with sample location. Increasing evidence demonstrates that genetic aberrations in cancer cells are key in the pathophysiology of cancer, however, the crosstalk among cancer cells, non-malignant cells, cytokines, growth factors and other participants in the TME (26). In all sections that were examined, the presence of E-cadherin, CRB3, PAR-3, Col-I, Hyal-1, CD1, CD133, vimentin, CK18 and $\alpha$-SMA were observed by IHC (Figs. 3 and 4). The expression of E-cadherin, CRB3 and PAR-3 in No. 1 and No. 2 was significantly higher than in No. 3 $(\mathrm{P}<0.05)$, and the majority of the expression was observed in the membrane of crypt cells (Fig. 2).

E-cadherin is a marker of epithelial-mesenchymal transition (EMT) (27), and it contributes to the development and metastasis of cancer, as decreased expression levels are observed in cancer tissues, it is considered an inhibitor of EMT (28). E-cadherin expression is regulated by a variety of protein molecules, including osteopontin (OPN) (29), and N-Myc downstream-regulated gene 2 (NDRG2) (30). An

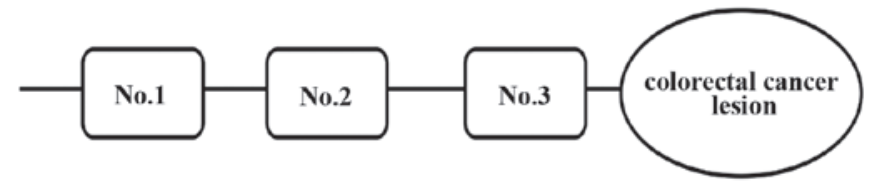

Figure 1. Sampling methods in the present study. Samples No. 1, No. 2 and No. 3 were $\geqq 10 \mathrm{~cm}, 5 \mathrm{~cm}$ and $\leqq 2 \mathrm{~cm}$ from the proximal location of the colorectal cancer lesion, respectively).

in vitro model demonstrates that ectopic expression of the onco-protein OPN induced colorectal cancer cell migration via E-cadherin repression (29), which may elucidate an underlying mechanism for the decreased expression of E-cadherin in sample No. 3. However, NDRG2, a differentiation-associated tumor suppressor, positively regulates the expression of E-cadherin (30). This suggests E-cadherin regulation is mediated by positive feedback and negative feedback through different signaling pathways.

Three evolutionary conserved polarity complexes, the Scribble, PAR and CRB complexes act as regulators of apical-basal polarity, however, tight junction integrity is predominantly maintained by the CRB and PAR polarity complexes (31). When normal tissues undergo canceration, cell polarity is also altered. For example, immortal neonatal mouse kidney epithelial cells with tumorigenicity exhibited repressed CRB3, associated with disruption of tight junctions and apicobasal polarity, in addition to promoting migration and metastasis (32). PAR-3, a PDZ protein, involved in the formation of junctional complexes in epithelial cells (33), has been observed in the distal resection margin of rectal cancer in a similar study that demonstrated that samples taken $3 \mathrm{~cm}$ from the tumor tissues had marked expression of PAR-3, while expression in the samples taken $2 \mathrm{~cm}$ away and in the tumor samples was relatively weak (34), which is consistent with the results of the present study. Interaction of PAR-3 and other proteins is frequently observed. T-lymphoma invasion and metastasis-inducing protein 1 (Tiam1) and its interactor $\beta 2$-syntrophin are required for optimal cell-cell adhesion, notably, the repression of Tiam1-Rac activity by PAR-3 facilitates tight-junction assembly (35), in addition to the interaction of PAR-3 and CRB3 (8) suggesting that the two proteins may have similar functions in a synergetic manner, as demonstrated in the present study, which demonstrated that the expression levels of the two proteins were associated (Fig. 5).

By contrast, the expression levels of Col-I, Hyal-1, CD1, CD133, vimentin and $\alpha$-SMA in samples No. 2 and No. 3 were significantly higher than in sample No. $1(\mathrm{P}<0.05)$. However, the expression profile of CK18 was different, in samples No. 2 and No. 3 its expression was lower than in sample No. 1 $(\mathrm{P}<0.05)$. Downregulation of CK18 was also demonstrated in the CRC SW480 cell line (36) and 468 CRC samples (22). The above results and functional cluster analysis, as presented in Figs. 5 and 6 suggests CK18 and CRB3 may have certain similar but not identical regulatory mechanisms. Furthermore, the expression levels of CK18, CD1, vimentin and $\alpha$-SMA were observed in mesenchymal tissue and CD133 was predominantly distributed in the crypt (Fig. 3).

Vimentin, a mesenchymal marker, is notably increased in $\mathrm{CRC}$, accompanied by reduced epithelial markers, 


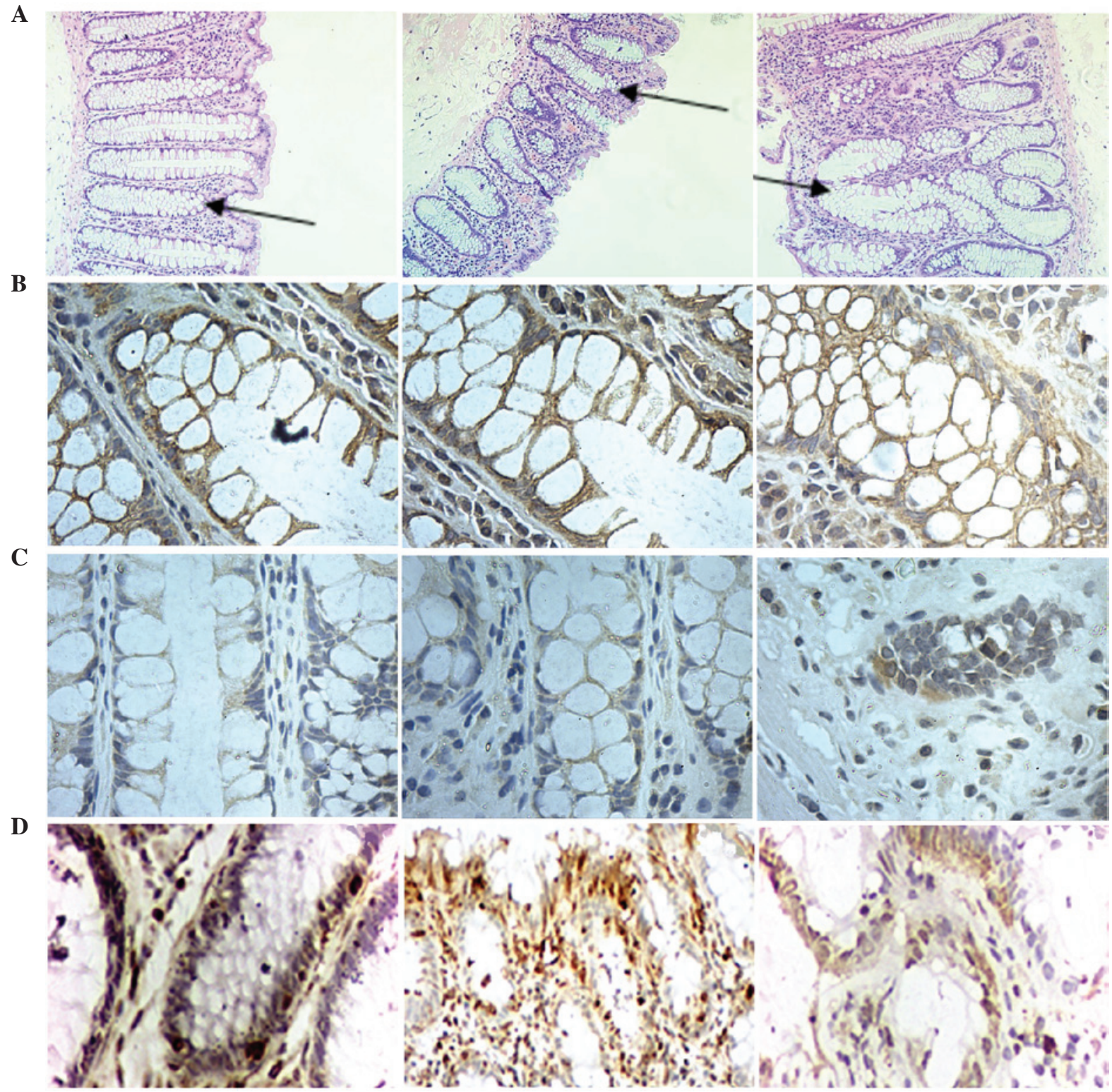

Figure 2. Staining of crypt structures. (A) Hematoxylin and eosin staining of samples no. 1,2 and 3 (left to right). Arrows indicate the locations of aberrant crypt foci. Protein expression levels of (B) E-cadherin, (C) Crumbs3 and (D) proteinase activated receptor 3 demonstrated by immunohistochemical staining in samples no. 1,2 and 3 (left to right).

E-cadherin and $\beta$-catenin, and is associated with regulation of dachshund homolog 1 (DACH1), a tumor suppressor (37) whose inhibition markedly increases cell growth, migration and invasion of SW480 cells. Its expression is also associated with proline rich 11, a newly identified oncogene that is overexpressed in colorectal cancer (38). In addition to the regulation of DACH1, the regulator transforming growth factor- $\beta$ (TGF- $\beta$ ), a factor in microenvironment, also exerts an effect on vimentin. For example, in an in vitro study, TGF- $\beta 1$ reduces E-cadherin expression and increases the vimentin expression (39). A previous study has demonstrated that vimentin is induced by Bcl-2-like protein 2 a pro-survival protein, via activating the transcription factors, $\beta$-catenin, Twist-related protein 1 and zinc finger protein Snail (40). Together with the above data, this suggests that vimentin is an important mediator of multiple signal proteins, thus exerting a vital effect in tumorigenesis.
CD133 also has a close association with vimentin, and is emerging as a marker of cancer stem cells (CSCs) (19). As presented in Figs. 3, 5 and 6, they have the similar profiles of expression, suggesting that they may have similar roles in cancer. However, CD133 is markedly affected by micromilieu, including hypoxia in TME (19). In CRC cell lines, downregulated CD133 expression is observed at $0.1 \%$ oxygen (41), consistent with an emerging hypothesis that CD133 is predominantly located in the inner core of the cancer mass (42) in which the hypoxic environment is located. Regulation of stem cell state is dynamic with the environment, as demonstrated in the present study where CD133 expression in sample No. 3 is increased. In addition, CD133 expression is also associated with EMT as previously demonstrated in a highly migratory subclone of the Capan-1 pancreatic cancer cell line (43).

Stromal cells in the TME, including fibroblasts contribute to human cancer cell engraftment and cancer progression (44). In 

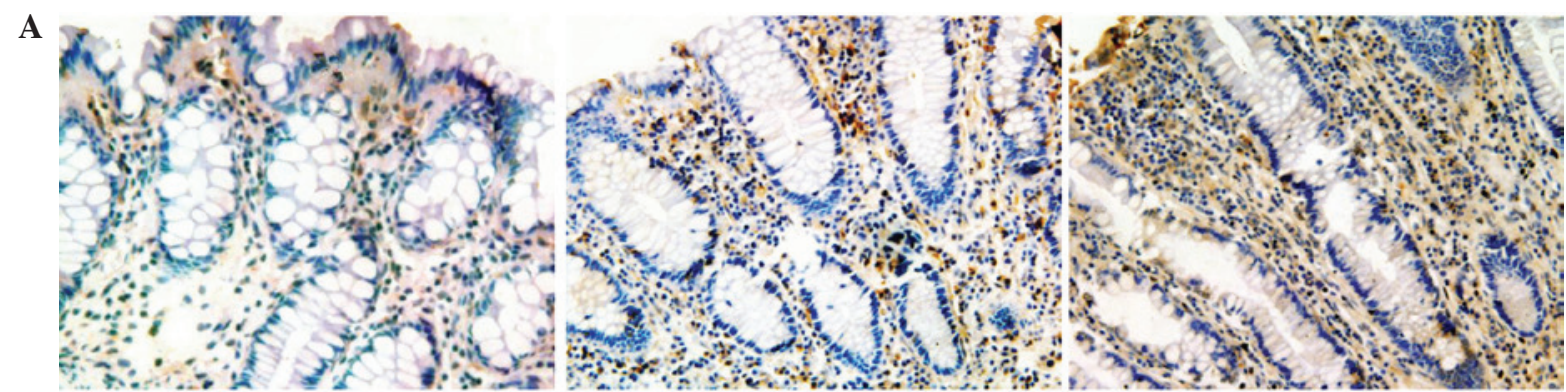

B
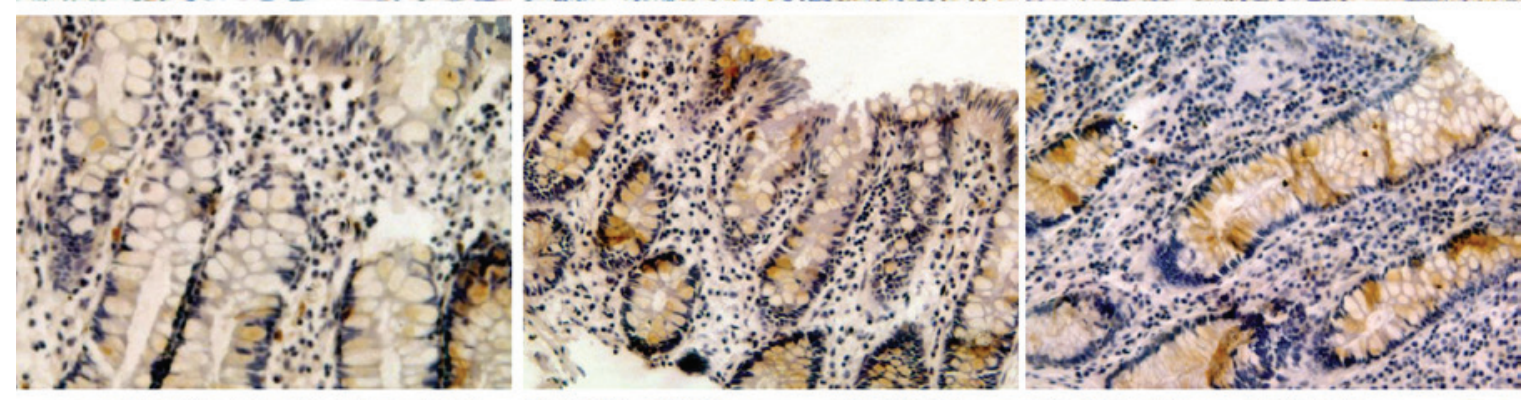

C
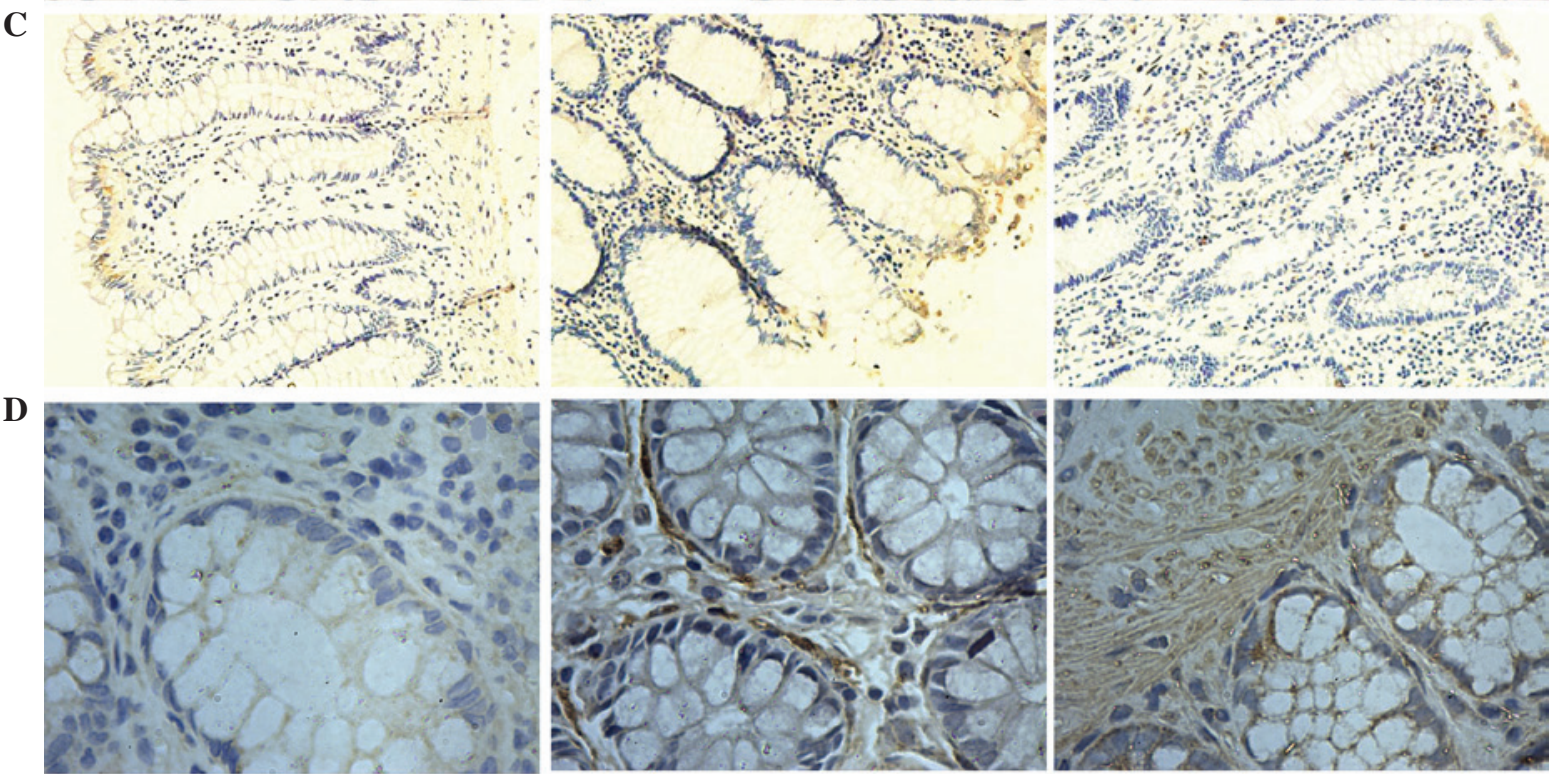

$\mathbf{E}$
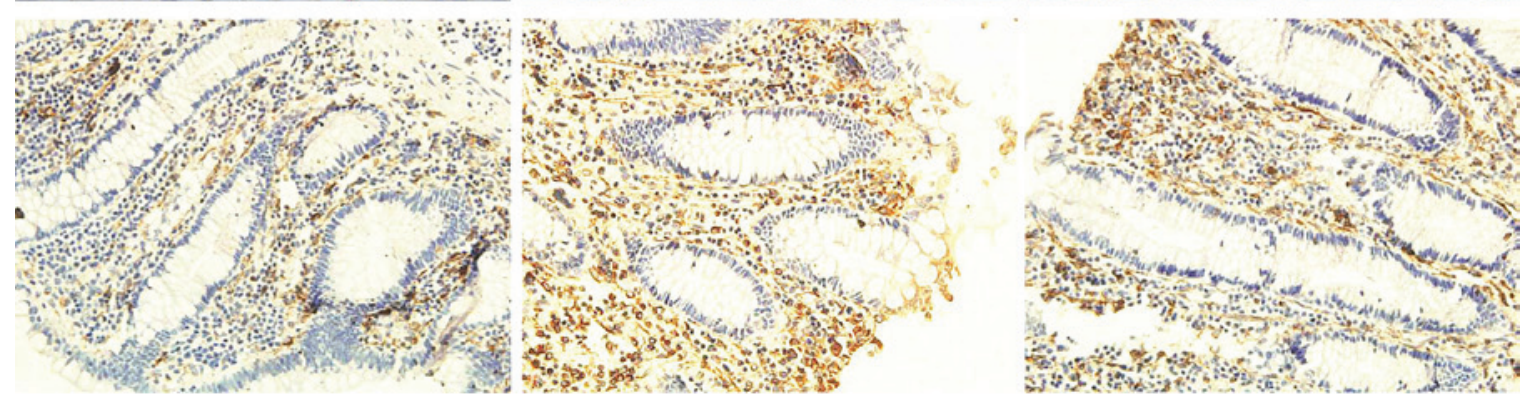

Figure 3. Expression levels of CD1, CD133, CK18, $\alpha$-SMA and vimentin indicated by immunohistochemical staining. Expression levels of (A) CD1, (B) CD133, (C) CK18, (D) $\alpha$-SMA and (E) vimentin, in samples no. 1, 2 and 3 (left to right). CD1, cyclin D1; CD133, cluster of differentiation 133; CK18, cytokeratin 18; $\alpha$-SMA, $\alpha$-smooth muscle actin.

the TME, interaction of activated cancer-associated fibroblasts (CAFs), with $\alpha$-SMA as a characteristic marker, and tumor cells promotes the production of CSCs exhibiting multipotency, indefinite self-renewal and asymmetric cell division (19), resulting in growth of cancer masses and cancer progression. This underlies CD133 being predominantly observed in ACF.

Snaill, a transcriptional factor that is important in EMT, is upregulated in CAFs and is associated with $\alpha$-SMA (45).
Researches have found that Snaill is required for the pro-tumorigenic effects of activated fibroblasts on CRC cells (45). In addition, the presence of $\alpha$-SMA expression at E-cadherin downregulated sites is demonstrated by IHC staining (46), consistent with the present study as $\alpha$-SMA expression in samples No. 3 and No. 2 were increased compared with sample No. 1, which implies activation of fibroblasts and induction of EMT. 
A

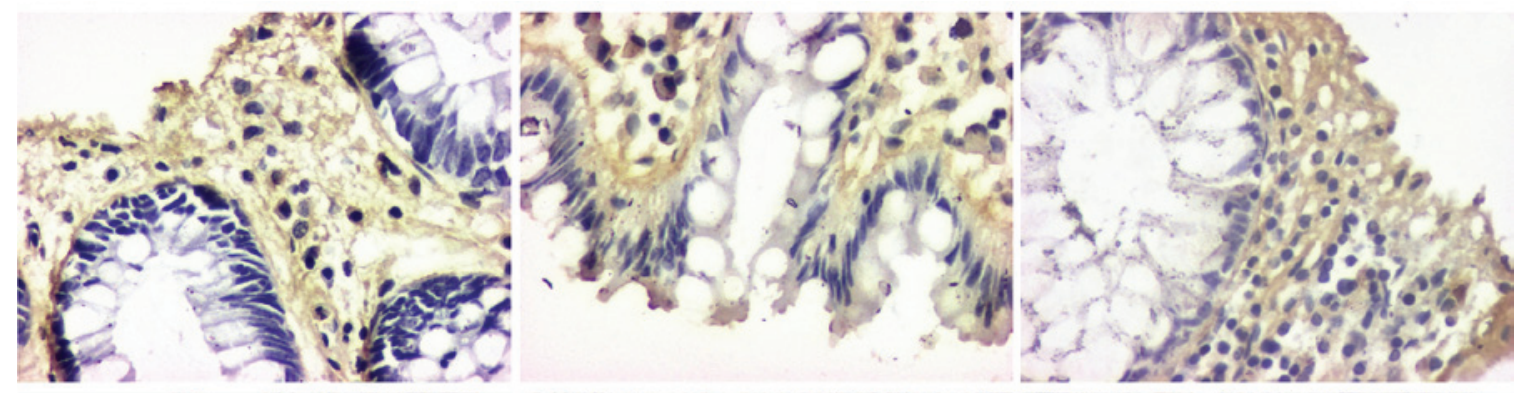

B
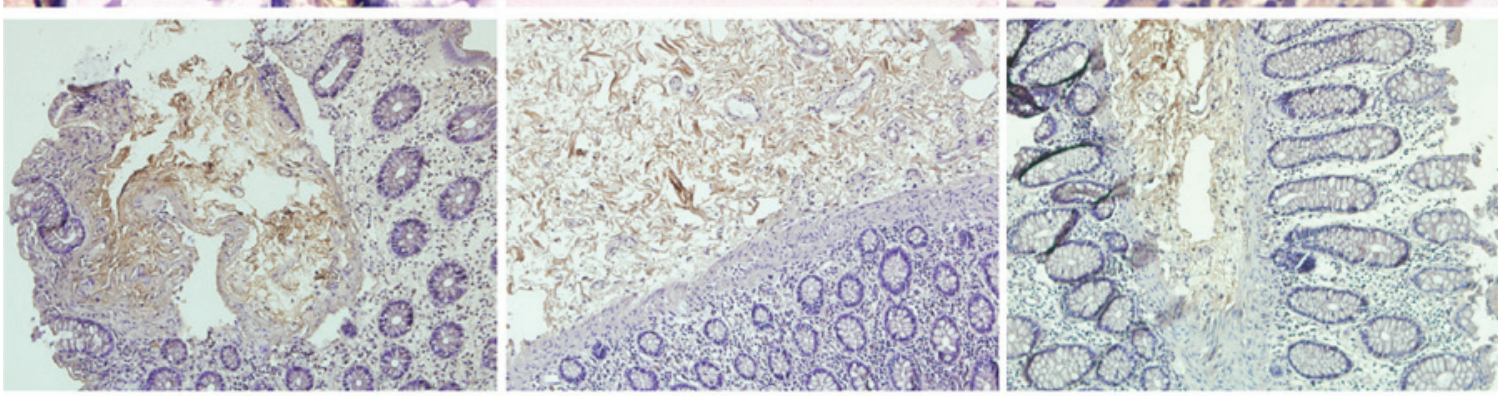

C
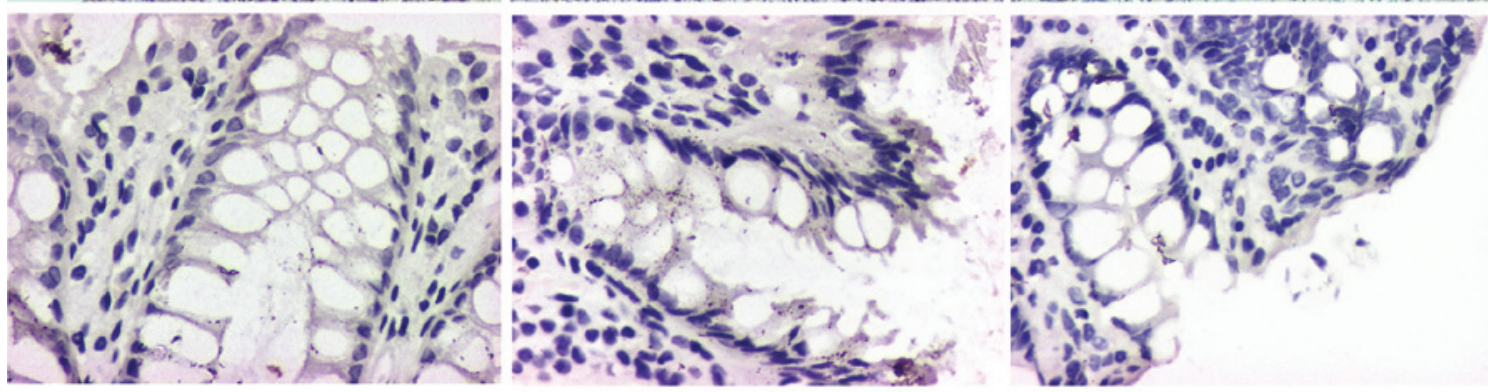

Figure 4. Expression of Col-I and Hyal-1 in three locations as demonstrated by immunohistochemical staining. Expression levels of (A) Col-I, (B) Hyal-1 in samples no. 1, 2 and 3 (left to right), and (C) negative staining in three locations as a negative control. Col-I, collagen type I; Hyal-1, hyaluronidase 1.

$\mathrm{CD} 1$ is a positive cell cycle regulator involved in $\mathrm{G}_{1} / \mathrm{S}$ and $\mathrm{G}_{2} / \mathrm{M}$ checkpoint transitions, resulting in CRC cell proliferation (47), and is positively regulated by transcription factor paired box 2 via activator protein 1 (48) and by $\beta$-catenin (49). Increased expression of CD1 is observed in tumor tissues. However, its upregulation was also observed in precancerous lesions in the present study, suggesting that CD1 may serve as a pro-oncogene via interaction with oncogene c-Myc and associated signals involving phosphoinositide 3-kinase/Akt/glycogen synthase kinase- $3 \beta$ signaling $(49,18)$.

The current study demonstrates that Col-I and Hyal-1 expression was predominantly distributed in the connective tissues (Fig. 4). Col-I is secreted from activated hepatic stellate cells, and it is considered to be associated with EMT (46). A previous study has demonstrated that Col-I may interact with integrin $\alpha v \beta 8$ leading to the upregulation of the latter, and resulting in proliferation and invasion of carcinoma cells via activation of the mitogen-activated protein kinase kinase/extracellular signal-regulated kinase signaling pathway (50). There are fewer similar studies investigating the role of Hyal-1 in colorectal cancer is relatively few, however, notably, a previous study suggests that reduced Hyal-1 is observed in human endometrial cancer and is associated with cancer progression involving a possible mechanism involving reduced E-cadherin expression (51). In addition, Hyal-1 expression is likely to be dependent on cancer types (51), consistently with this previous study, the expression profile of Hyal-1 was the same as E-cadherin in samples No. 1 and No. 2, however, it was different in sample No. 3, which suggests Hyal-1 expression in pre-malignant tissues is not regulated via the above mechanism.

Related function analysis using hierarchical index cluster indicated the importance of Col-I and Hyal-1 in tumorigenesis. For functional analysis of the proteins, index clustering was used. As presented in Fig. 6, all these protein molecules mentioned were divided into two large groups, one containing Hyal-1 and Col-I, and the other containing was the other investigated proteins. From this clustering, it can be determined that certain proteins may have the same, similar or synergetic functions during canceration, in addition to the same or similar regulatory mechanisms. For example, E-cadherin upregulation, and downregulation of vimentin, cyclin-D1, and $\alpha$-SMA are mediated by microRNA-494 in breast cancer cells (52).

Cell polarity, an essential feature in eukaryotic cells, is the determinant of cellular morphology. It is important in asymmetric division and tight junctions. Disrupted polarity is also considered to be a characteristic of cancer (53).

Hyal-1 and Col-I are key in tumorigenesis. Col-I is produced by fibroblasts (54), remodeling of the ECM may result in a pre-cancerous niche, which could lead to a chronic stress escape strategy (CSES) during carcinogenesis. The terminal consequence is a normal-cell to cancer-cell transition (1). Notably, the TME and ECM must generate conditions in favor of metastatic cancers proliferation at certain locations 

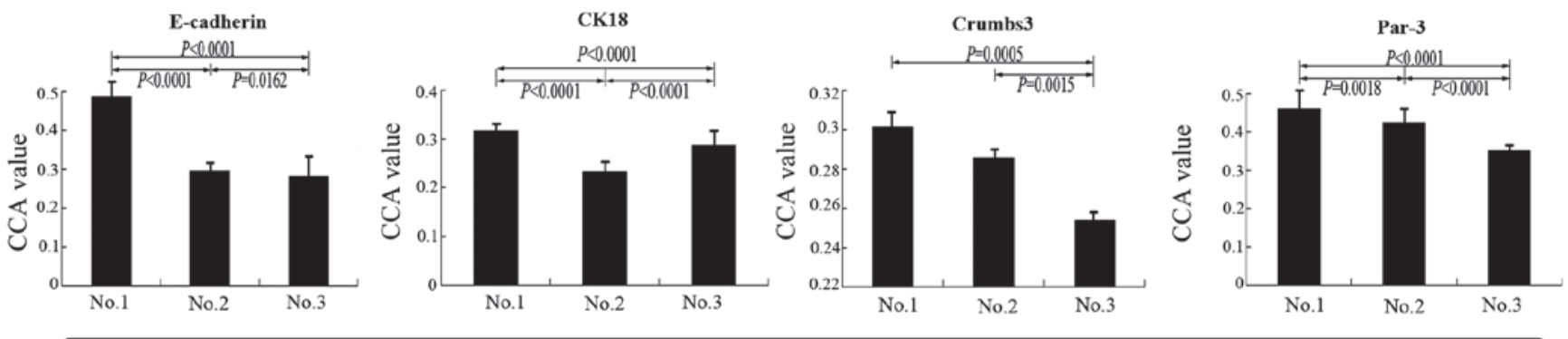

Sampling locations
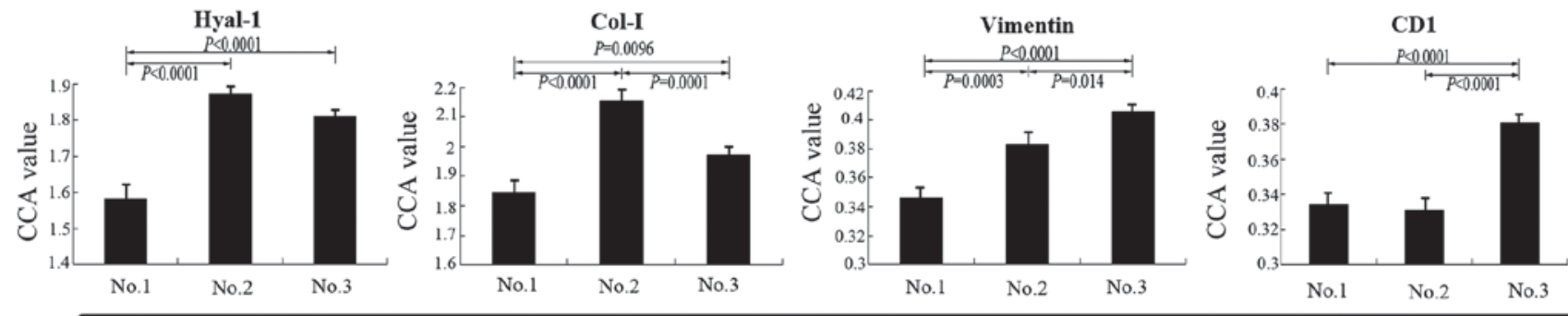

Sampling locations

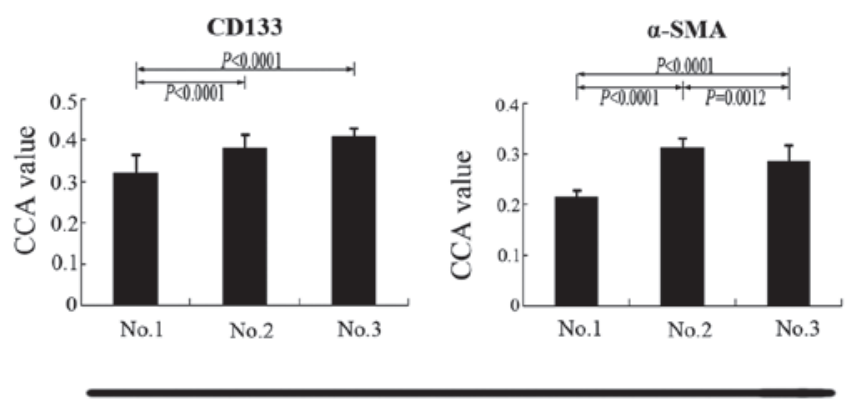

Sampling locations

Figure 5. CCA value of ten biomarkers in samples No. 1, No. 2 and No. 3. Demonstrated by the CCA value, the expression levels of E-cadherin, CK18, Crumbs-3 and Par-3 in sample No. 3 were lower compared with sample No. $1(\mathrm{P}<0.05)$. The expression of CK18 in sample No. 2 was lower than in sample No. $3(\mathrm{P}<0.0001)$. The expression levels of Hyal-1, Col-I, vimentin, CD1, CD133 and $\alpha$-SMA in sample No. 3 were higher than in sample No. $1(\mathrm{P}<0.05)$, however, the expression levels of Hyal-1, Col-I, $\alpha$-SMA in sample No. 3 were lower than that in sample No. 2, the result for Hyal-1 was not significant. CCA, corrected absorbance value; CK18, cytokeratin 18; Par-3, proteinase activated receptor 3; Hyal-1, hyaluronidase 1; Col-I, collagen type I; CD1, cyclin D1; CD133, cluster of differentiation 133; $\alpha$-SMA, $\alpha$-smooth muscle actin.

but not at others (55). The expression of the Hyal-1 and Col-I presents different profiles in different sites, which suggests, together with the functional analysis, that Hyal-1 and Col-I may be important in tumorigenesis.

\section{Discussion}

There is an emerging hypothesis that tumors function as a complex organ similar to normal tissues. The various cell types and components of surrounding tumor microenvironment are involved in tumorigenesis (56). Phenotypic and epigenetic changes have been observed in the cells and the stroma during tumor initiation and progression. The microenvironment, or niche, in tumor tissue is suggested to provide essential support for the aberrant growth of tumor stem cells (57). Cells are associated with the surrounding environment and stroma are associated with the basal membrane from which information can be transmitted and processed (55).

The asymmetrical distribution of cell polarity divides the cellular domains into different structural and functional areas in which cells can interact with surrounding extracellular environments. Cell polarity is key for controlling cell behavior and loss of cell polarity promotes tumor initiation. E-cadherin, which localizes at the lateral membrane, is vital to the formation of the adherens junctions. However, CRB3 is located in the apical pole and its loss contributes to phenotypic changes, such as EMT. Lateral growth factor receptors are exposed to apical ligands following downregulation of CRB3 and disruption of tight junctions. This process may deregulate cell growth and promote proliferation. Furthermore, decreased CRB3 may alter cellular behaviors contributing to motility and migration (58). Tight junctions separate the basolateral and apical cellular domains in epithelial cells vital for establishing and maintaining cell morphology. PAR-atypical protein kinase C complex is recruited to the cell cortex from the cytoplasm during the formation of tight junctions (59). PAR3 combines the junctional adhesion molecules, including junctional adhesion molecule-1 and nectin $(60,61)$. Cell polarity is important in the maintenance of normal crypt organization and structure. Downregulation of E-cadherin, CRB3 and PAR3 in sample No. 3 suggests that polarity proteins may promote tumorigenesis in human carcinomas via controlling cell behavior. 


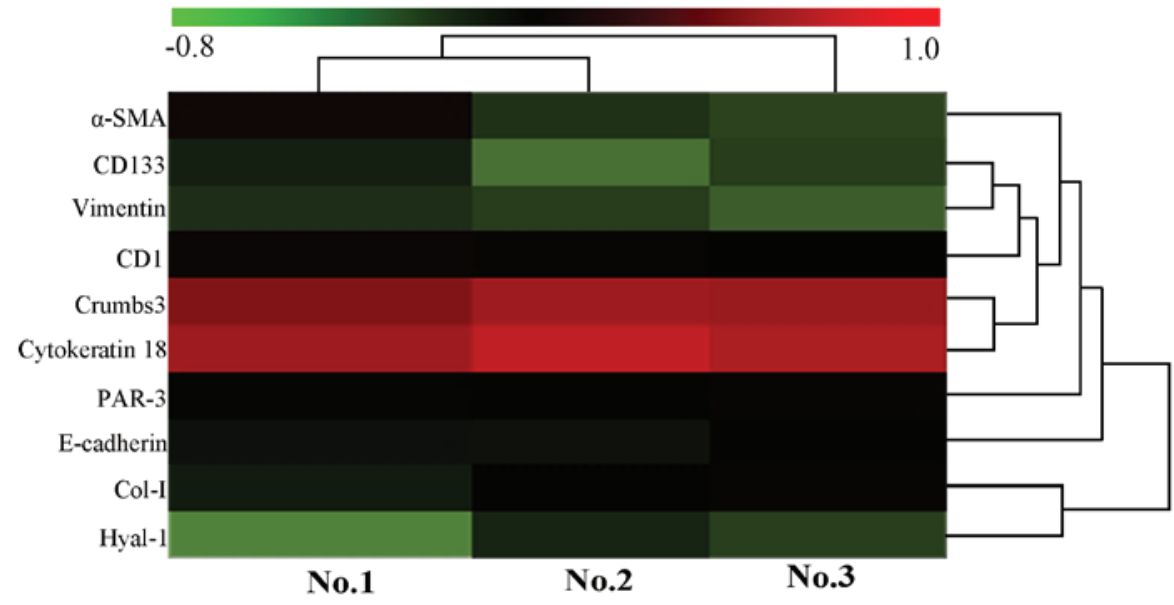

Figure 6. Heatmap of biomarker expression in the present study according to the CCA value of samples No. 1, No. 2 and No. 3. The heatmap diagram indicates the result of the two-way hierarchical clustering of markers and samples. Each row represents a marker and each column represents a sample. The marker clustering tree is presented on the right, and the sample clustering tree at the top. Cluster analysis arranges samples and markers into groups based on their CCA values, which allows formation of hypotheses regarding the association between markers and samples. The color of each pattern indicates the CCA value, green to red is -0.8 to 1.0. CCA, corrected absorbance value; $\alpha$-SMA, $\alpha$-smooth muscle actin; CD1, cyclin D1; CD133, cluster of differentiation 133; PAR-3, proteinase activated receptor 3; Col-I, collagen type I; Hyal-1, hyaluronidase 1.

In the progression of cancer, the expression of ECM components is upregulated, downregulated or lost, promoting tumor initiation and progression. ECM is important in cell growth and interaction. Cell-cell and cell-ECM interaction is involved in tumorigenesis. Cell-cell communication in microenvironment is necessary for morphogenesis, cell differentiation, homeostasis, cell growth, and cell-cell interaction. Notably, cell-cell communication is described as 'the music that the nucleus hears' and, the health of the organism is likely to be damaged by aberrant cell-cell communication (62).

Hyaluronan is key in cancer development and tumorigenesis, including tumor growth, infiltration and angiogenesis $(63,64)$. Hyal-1 is a primary tumor-derived enzyme expressed by various different types of tumor cell. Hyaluronan interacts with other proteoglycans to maintain the structural integrity required in tissue homeostasis. Hyaluronan contributes to basic cellular behavior, such as cell adhesion, cell recognition and cell migration $(65,66)$. Thus, hyaluronan is important in tissue morphogenesis, tissue remodeling and tumor growth. In CRC, hyaluronan promotes tumor cell migration and proliferation. It may also stimulate anchorage-independent growth and protect against immune surveillance (67). Furthermore, tumor cells may be more aggressive to invade into surrounding tissues with hyaluronan-rich ECM. Hyaluronidases have been reported to function like tumor inhibitors in vivo (68). Collagens are part of connective tissues and the predominant component of the ECM. They have a marked effect on structural stability and integrity. Degradation of collagen and aberrant metabolism are important in tumorigenesis. Collagens contribute to tissue repair and regeneration by their binding capacity with other growth factors, including hepatocyte growth factor (69-73). In numerous types of malignant tumor, including colorectal adenocarcinoma, Col-I and III are the primary components of ECM. Increased Col-I has been demonstrated to be associated with tumor malignancy (74). Increasing expression of Hyal-1 and Col-I from sample No. 1 to sample No. 3 in the present study also indicates these may promote tumor initiation and progression.

Fibroblasts and myofibroblasts produce the increased quantity of collagen in cancer (75). Myofibroblasts and abnormal fibroblasts are recruited during tumorigenesis, promoting tumor cell proliferation, angiogenesis, and metastasis. Cancer-associated fibroblasts (CAFs) are also important in the tumor microenvironment, functioning in cancer initiation and progression, which has been previously investigated (76). $\alpha$-SMA is a common marker for detecting the expression of myofibroblasts and vimentin. Furthermore, vimentin enhances motility. The tumor size and growth rate of MCF7 breast cancer cells suspended in fibroblast conditioned medium were increased, demonstrating that the soluble factors secreted by fibroblasts may contribute to tumor progression (77). A large number of CAFs, distinct from normal fibroblasts, exist in the cancer microenvironment. TGF- $\beta$ and hepatocyte growth factor secreted by CAFs promote EMT and tumor metastasis. In addition, the transition from one cell function to another, or the transition of one cell type to another appears to be a routine event rather than a rare one. EMT can induce non-cancer stem cells to become cancer stem cells (78). Colorectal cancer stem cells are a small subpopulation of tumor cells that have been proposed to be tumor-initiating cells in CRC (79). Furthermore, CAFs stimulate tumor cell proliferation directly by secreting a variety of growth factors, hormones and cytokines (80). A number of these secreted factors promote transformation of epithelial cells. The expression levels of $\alpha$-SMA and vimentin were upregulated in samples No. 2 and No. 3 suggesting that myofibroblasts and fibroblasts served as positive factors in tumor initiation. CD1, an important regulator of the $\mathrm{G}_{1^{-}}$to $\mathrm{S}$-phase transition and cell proliferation (81), has been reported to be important in cancer progression (82). CD1 is also considered to be an oncogenic marker in a number of types of human cancer. CD133 has been identified as a biomarker for cancer stem cells, which can promote tumorigenesis, tumor cell proliferation, differentiation, metastasis, self-renewal and 
treatment resistance. The results of the present study demonstrated that expression of CD1 and CD133 was increased in sample No. 3 compared with No. 1 and No. 2, indicating that they may be important indicators for colorectal cancer.

It has been increasingly recognized that ECM regulates gene expression by cell surface integrin receptors $(83,84)$. Intermediate filaments are transducers between cell surface integrins and nuclei $(85,86)$. Integrins with bidirectional communicating features mediating the information exchanged between cells and their surrounding components allow a flow of information in two directions, enabling the signal transduction of bidirectional information exchange between the ECM and the cell $(87,88)$. CK18 is the predominant intermediate filament protein of epithelial cells and epithelial-derived tumors, accounting for $\sim 5 \%$ of the total cell protein. CK18 promotes cellular collapse and apoptosis. The potential of increased CK18 as a marker for CRC has been tested by qPCR in CRC tissue samples (89). The loss of epithelial CK18 and the overexpression of vimentin in sample No. 3 indicates that EMT may be occurring during tumorigenesis.

In conclusion, to the best of our knowledge, the present study indicates that co-evolution of a tumor and its microenvironment occurs spontaneously in human colorectal cancer. Targeting the components of the cancer microenvironment may be a potential approach for cancer diagnosis and prevention. Future investigations in this field should aim to integrate tissue culture studies and analyses in animal models representing early stages of cancer development. The present study increases the understanding of communication within the cancer microenvironment, which may aid the development of early diagnosis or preventive strategies based on this.

\section{Acknowledgements}

The authors would like to thank Liyun Wu and Meng Su for their technical assistance. The present study is funded by the National Natural Science Foundation of China (grant no. 81173257) and The Central Government Funds Supporting the Development of Local Colleges and Universities For the Prevention Collaborative Innovation Platform of Major Refractory Spleen and Stomach Diseases [grant no. (2013) 338].

\section{References}

1. Brücher BL and Jamall IS: Epistemology of the origin of cancer: A new paradigm. BMC Cancer 14: 331, 2014.

2. Paget $S:$ The distribution of secondary growths in cancer of the breast 1889. Cancer Metastasis Rev 8: 98-101, 1989.

3. Korkaya H, Liu S and Wicha MS: Breast cancer stem cells, cytokine networks, and the tumor microenvironment. J Clin Invest 121: 3804-3809, 2011.

4. Felsher DW: Cancer revoked: Oncogenes as therapeutic targets. Nat Rev Cancer 3: 375-380, 2003.

5. Li R and Pendergast AM: Arg kinase regulates epithelial cell polarity by targeting $\beta 1$-integrin and small GTPase pathways Curr Biol 21: 1534-1542, 2011.

6. Hammoudi A, Song F, Reed KR, Jenkins RE, Meniel VS, Watson AJ, Pritchard DM, Clarke AR and Jenkins JR: Proteomic profiling of a mouse model of acute intestinal Apc deletion leads to identification of potential novel biomarkers of human colorectalcancer (CRC). Biochem Biophys Res Commun 440: 364-370, 2013.

7. Elsum IA, Martin C and Humbert PO: Scribble regulates an EMT polarity pathway through modulation of MAPK-ERK signaling to mediate junction formation. J Cell Sci 126 3990-3999, 2013.
8. Sfakianos J, Togawa A, Maday S, Hull M, Pypaert M, Cantley L, Toomre D and Mellman I: Par3 functions in the biogenesis of the primary cilium in polarized epithelial cells. J Cell Biol 179: 1133-1140, 2007

9. Reed MJ, Damodarasamy M, Chan CK, Johnson MN, Wight TN and Vernon RB: Cleavage of hyaluronan is impaired in aged dermal wounds. Matrix Biol 32: 45-51, 2013.

10. Tlsty TD and Hein PW: Know thy neighbor: Stromal cells can contribute oncogenic signals. Curr Opin Genet Dev 11: 54-59, 2001.

11. Weinberg R and Mihich E: Eighteenth annual pezcoller symposium: Tumor microenvironment and heterotypic interactions. Cancer Res 66: 11550-11553, 2006.

12. Roncucci L, Pedroni M, Vaccina F, Benatti P, Marzona L and De Pol A: Aberrant crypt foci in colorectal carcinogenesis. Cell and crypt dynamics. Cell Prolif 33: 1-18, 2000.

13. Hanahan D and Weinberg RA: Hallmarks of cancer: The next generation. Cell 144: 646-674, 2011.

14. Guo F, Wang Q, Zhou Y, Wu L, Ma X, Liu F, Huang F and Qin G: Lentiviral vector-mediated FoxO1 overexpression inhibits extracellular matrix protein secretion under high glucose conditions in mesangial cells. J Cell Biochem 117: 74-83, 2016.

15. Kolliopoulos C, Bounias D, Bouga H, Kyriakopoulou D, Stavropoulos $\mathrm{M}$ and Vynios DH: Hyaluronidases and their inhibitors in the serum of colorectal carcinoma patients. J Pharm Biomed Anal 83: 299-304, 2013.

16. Barreto SC,Hopkins CA, Bhowmick M and Ray A: Extracellular matrix in obesity-cancer interactions. Horm Mol Biol Clin Investig 22: 63-77, 2015.

17. Abu El-Asrar AM, De Hertogh G, van den Eynde K, Alam K, Van Raemdonck K, Opdenakker G, Van Damme J, Geboes K and Struyf S: Myofibroblasts in proliferative diabetic retinopathy can originate from infiltrating fibrocytes and through endothelial-to-mesenchymal transition (EndoMT). Exp Eye Res 132: $179-189,2015$.

18. Noah TK, Lo YH, Price A, Chen G, King E, Washington MK, Aronow BJ and Shroyer NF: SPDEF functions as a colorectal tumor suppressor by inhibiting $\beta$-catenin activity. Gastroenterology 144: 1012-1023.e6, 2013.

19. Grosse-Gehling P, Fargeas CA, Dittfeld C, Garbe Y, Alison MR, Corbeil D and Kunz-Schughart LA: CD133 as a biomarker for putative cancer stem cells in solid tumours: Limitations, problems and challenges. J Pathol 229: 355-378, 2013.

20. Wang P: Suppression of DACH1 promotes migration and invasion of colorectal cancer via activating TGF- $\beta$-mediated epithelial-mesenchymal transition. Biochem Biophys Res Commun 460: 314-319, 2015.

21. Lai DW, Liu SH, Karlsson AI, Lee WJ, Wang KB, Chen YC, Shen CC, Wu SM, Liu CY, Tien HR, et al: The novel Aryl hydrocarbon receptor inhibitor biseugenol inhibits gastric tumor growth and peritoneal dissemination. Oncotarget 5: 7788-7804, 2014.

22. Knösel T, Emde V, Schlüns K, Schlag PM, Dietel M and Petersen I: Cytokeratin profiles identify diagnostic signatures in colorectal cancer using multiplex analysis of tissue microarrays. Cell Oncol 28: 167-175, 2006

23. Cernat L, Blaj C, Jackstadt R, Brandl L, Engel J, Hermeking H, Jung A, Kirchner T and Horst D: Colorectal cancers mimic structural organization of normal colonic crypts. PLoS One 9: e104284, 2014.

24. Milicic A, Harrison LA, Goodlad RA, Hardy RG, Nicholson AM, Presz M, Sieber O, Santander S, Pringle JH, Mandir N, et al: Ectopic expression of P-cadherin correlates with promoter hypomethylation early in colorectal carcinogenesis and enhanced intestinal crypt fission in vivo. Cancer Res 68: 7760-7768, 2008.

25. Whiteman EL, Liu CJ, Fearon ER and Margolis B: The transcription factor snail represses Crumbs 3 expression and disrupts apico-basal polarity complexes. Oncogene 27: 3875-3879, 2008.

26. Ribeiro AL and Okamoto OK: Combined effects of pericytes in the tumor microenvironment. Stem Cells Int 2015: 868475, 2015.

27. Kim MJ, Lee YS, Han GY, Lee HN, Ahn C and Kim CW: Profilin 2 promotes migration, invasion, and stemness of HT29 human colorectal cancer stem cells. Biosci Biotechnol Biochem 79: 1438-1446, 2015.

28. Chen CC, Sureshbabul M, Chen HW, Lin YS, Lee JY, Hong QS, Yang YC and Yu SL: Curcumin suppresses metastasis via Sp-1, FAK inhibition and E-Cadherin upregulation in colorectal cancer. Evid Based Complement Alternat Med 2013: 541695, 2013. 
29. Ng L, Wan TM, Lam CS, Chow AK, Wong SK, Man JH, Li HS, Cheng NS, Pak RC, Cheung AH, et al: Post-operative plasma osteopontin predicts distant metastasis in human colorectal cancer. PLoS One 10: e0126219, 2015.

30. Kim YJ, Kang HB, Yim HS, Kim JH and Kim JW: NDRG2 positively regulates E-cadherin expression and prolongs overall survival in colon cancer patients. Oncol Rep 30: 1890-1898, 2013.

31. Elsum IA, Martin C and Humbert PO: Scribble regulates an EMT polarity pathway through modulation of MAPK-ERK signaling to mediate junction formation. J Cell Sci 126 : 3990-3999, 2013.

32. Karp CM, Tan TT, Mathew R, Nelson D, Mukherjee C, Degenhardt K, Karantza-Wadsworth V and White E: Role of the polarity determinant crumbs in suppressing mammalian epithelial tumor progression. Cancer Res 68: 4105-4115, 2008.

33. Sfakianos J, Togawa A, Maday S, Hull M, Pypaert M, Cantley L, Toomre D and Mellman I: Par3 functions in the biogenesis of the primary cilium in polarized epithelial cells. J Cell Biol 179: $1133-1140,2007$

34. Liu J, Zhang W, Liu J, Lu X, Long Y, Zhou Y and Liu S: Expressions of connexin and par-3 in the distal margin of rectal cancer after ultra-low anterior resection. J Huazhong Univ Sci Technolog Med Sci 29: 330-334, 2009.

35. Mack NA, Porter AP, Whalley HJ, Schwarz JP, Jones RC, Khaja AS, Bjartell A, Anderson KI and Malliri A: $\beta 2$-syntrophin and Par-3 promote an apicobasal Rac activity gradient at cell-cell junctions by differentially regulating Tiam1 activity. Nat Cell Biol 14: 1169-1180, 2012

36. Wong CS, Wong VW, Chan CM, Ma BB, Hui EP, Wong MC, Lam MY, Au TC, Chan WH, Cheuk W and Chan AT: Identification of 5-fluorouracil response proteins in colorectal carcinoma cell line SW480 by two-dimensional electrophoresis and MALDI-TOF mass spectrometry. Oncol Rep 20: 89-98, 2008.

37. Wang P: Suppression of DACH1 promotes migration and invasion of colorectal cancer via activating TGF- $\beta$-mediated epithelial-mesenchymal transition. Biochem Biophys Res Commun 460: 314-319, 2015.

38. Chen Y, Cha Z, Fang W, Qian B, Yu W, Li W, Yu G and Gao Y: The prognostic potential and oncogenic effects of PRR11 expression in hilar cholangiocarcinoma. Oncotarget 6 : 20419-20433, 2015

39. Ji Q, Liu X, Han Z, Zhou L, Sui H, Yan L, Jiang H, Ren J, Cai J and Li Q: Resveratrol suppresses epithelial-to-mesenchymal transition in colorectal cancer through TGF- $\beta 1 /$ Smads signaling pathway mediated Snail/E-cadherin expression. BMC Cancer 15 97, 2015.

40. Lee WS, Woo EY, Kwon J, Park MJ, Lee JS, Han YH and Bae IH: Bcl-w enhances mesenchymal changes and invasiveness of glioblastoma cells by inducing nuclear accumulation of $\beta$-catenin. PLoS One 8: e68030, 2013.

41. Matsumoto K, Arao T, Tanaka K, Kaneda H, Kudo K, Fujita Y, Tamura D, Aomatsu K, Tamura T, Yamada Y, et al: mTOR signal and hypoxia-inducible factor-1 alpha regulate CD133 expression in cancer cells. Cancer Res 69: 7160-7164, 2009

42. Pistollato F, Abbadi S, Rampazzo E, Persano L, Della Puppa A, Frasson C, Sarto E, Scienza R, D'avella D and Basso G: Intratumoral hypoxic gradient drives stem cells distribution and MGMT expression in glioblastoma. Stem Cells 28: 851-862, 2010.

43. Ding Q, Yoshimitsu M, Kuwahata T, Maeda K, Hayashi T, Obara T, Miyazaki Y, Matsubara S, Natsugoe S and Takao S: Establishment of a highly migratory subclone reveals that CD133 contributes to migration and invasion through epithelial-mesenchymal transition in pancreatic cancer. Hum Cell 25: 1-8, 2012

44. Tlsty TD and Coussens LM: Tumor stroma and regulation of cancer development. Annu Rev Pathol 1: 119-150, 2006.

45. Herrera A, Herrera M, Alba-Castellón L, Silva J, García V, Loubat-Casanovas J, Alvarez-Cienfuegos A, Migue García J, Rodriguez R, Gil B, et al: Protumorigenic effects of Snail-expression fibroblasts on colon cancer cells. Int J Cancer 134: 2984-2990, 2014.

46. Yang MC, Wang CJ, Liao PC, Yen CJ and Shan YS: Hepatic stellate cells secretes type I collagen to trigger epithelial mesenchymal transition of hepatoma cells. Am J Cancer Res 4: 751-763, 2014.

47. Feng Y, Xu X, Zhang Y, Ding J, Wang Y, Zhang X, Wu Z, Kang L, Liang Y, Zhou L, et al: HPIP is upregulated in colorectal cancer and regulates colorectal cancer cell proliferation, apoptosis and invasion. Sci Rep 5: 9429, 2015.
48. Zhang HS, Yan B, Li XB, Fan L, Zhang YF, Wu GH, Li M and Fang J: PAX2 protein induces expression of cyclin D1 through activating AP-1 protein and promotes proliferation of colon cancer cells. J Biol Chem 287: 44164-44172, 2012.

49. Park EJ, Chung HJ, Park HJ, Kim GD, Ahn YH and Lee SK Suppression of Src/ERK and GSK-3/ $\beta$-catenin signaling by pinosylvin inhibits the growth of human colorectal cancer cells. Food Chem Toxicol 55: 424-433, 2013.

50. Hayashido Y, Kitano H, Sakaue T, Fujii T, Suematsu M, Sakurai S and Okamoto T: Overexpression of integrin $\alpha \mathrm{v}$ facilitates proliferation and invasion of oral squamous cell carcinoma cells via MEK/ERK signaling pathway that is activated by interaction of integrin $\alpha v \beta 8$ with type I collagen. Int J Oncol 45: 1875-1882, 2014.

51. Nykopp TK, Pasonen-Seppänen S, Tammi MI, Tammi RH, Kosma VM, Anttila M and Sironen R: Decreased hyaluronidase 1 expression is associated with early disease recurrence in human endometrial cancer. Gynecol Oncol 137: 152-159, 2015.

52. Song L, Liu D, Wang B, He J, Zhang S, Dai Z, Ma X and Wang X: miR-494 suppresses the progression of breast cancer in vitro by targeting CXCR4 through the Wnt/ $\beta$-catenin signaling pathway. Oncol Rep 34: 525-531, 2015.

53. Cao F, Miao Y, Xu K and Liu P: Lethal (2) giant larvae: An indispensable regulator of cell polarity and cancer development. Int J Biol Sci 11: 380-389, 2015.

54. Mayne R, Vail MS and Miller EJ: Characterization of the collagen chains synthesized by cultured smooth muscle cells derived from rhesus monkey thoracic aorta. Biochemistry 17: 446-452, 1978

55. Brücher BL and Jamall IS: Cell-cell communication in the tumor microenvironment, carcinogenesis and anticancer treatment. Cell Physiol Biochem 34: 213-243, 2014.

56. Yamanaka T, Horikoshi Y, Suzuki A, Sugiyama Y, Kitamura K, Maniwa R, Nagai Y, Yamashita A, Hirose T, Ishikawa H and Ohno S: Par-6 regulates aPKC activity in a novel way and mediates cell-cell contact-induced formation of the epithelial junctional complex. Genes Cells 6: 721-731, 2001.

57. Guo J, Niu R, Huang W, Zhou M, Shi J, Zhang L and Liao H: Growth factors from tumor microenvironment possibly promote the proliferation of glioblastoma-derived stem-like cells in vitro. Pathol Oncol Res 18: 1047-1057, 2012.

58. Itoh M, Sasaki H, Furuse M, Ozaki H, Kita T and Tsukita S: Junctional adhesion molecule (JAM) binds to PAR-3: A possible mechanism for the recruitment of PAR-3 to tight junctions. J Cell Biol 154: 491-497, 2001

59. Ebnet K, Suzuki A, Horikoshi Y, Hirose T, Meyer Zu Brickwedde MK, Ohno S and Vestweber D: The cell polarity protein ASIP/PAR-3 directly associates with junctional adhesion molecule (JAM). EMBO J 20: 3738-3748, 2001.

60. Lokeshwar VB, Rubinowicz D, Schroeder GL, Forgacs E, Minna JD, Block NL, Nadji M and Lokeshwar BL: Stromal and epithelial expression of tumor markers hyaluronic acid and HYAL1 hyaluronidase in prostate cancer. J Biol Chem 276 11922-11932, 2001.

61. Lokeshwar VB, Young MJ, Goudarzi G, Iida N, Yudin AI, Cherr GN and Selzer MG: Identification of bladder tumor-derived hyaluronidase: Its similarity to HYAL1. Cancer Res 59: 4464-44670, 1999.

62. McCrea PD, Gu D and Balda MS: Junctional music that the nucleus hears: Cell-cell contact signaling and the modulation of gene activity. Cold Spring Harb Perspect Biol 1: a002923, 2009.

63. Menzel EJ and Farr C: Hyaluronidase and its substrate hyaluronan: Biochemistry, biological activities and therapeutic uses. Cancer Lett 131: 3-11,1998.

64. Turley EA, Noble PW and Bourguignon LY: Signaling properties of hyaluronan receptors. J Biol Chem 277: 4589-4592, 2002.

65. Paiva P, Van Damme MP, Tellbach M, Jones RL, Jobling T and Salamonsen LA: Expression patterns of hyaluronan, hyaluronan synthases and hyaluronidases indicate a role for hyaluronan in the progression of endometrial cancer. Gynecol Oncol 98: 193-202, 2005

66. Wang F, Grigorieva EV, Li J, Senchenko VN, Pavlova TV, Anedchenko EA, Kudryavtseva AV, Tsimanis A, Angeloni D, Lerman MI, et al: HYAL1 and HYAL2 inhibit tumour growth in vivo but not in vitro. PLoS One 3: e3031, 2008.

67. Lokeshwar VB, Cerwinka WH and Lokeshwar BL: HYAL1 hyaluronidase: A molecular determinant of bladder tumor growth and invasion. Cancer Res 65: 2243-2250, 2005. 
68. Kramer MW, Golshani R, Merseburger AS, Knapp J, Garcia A, Hennenlotter J, Duncan RC, Soloway MS, Jorda M, Kuczyk MA, et al: HYAL-1 hyaluronidase: A potential prognostic indicator for progression to muscle invasion and recurrence in bladder cancer. Eur Urol 57: 86-93, 2010.

69. Wakitani S, Kimura T, Hirooka A, Ochi T, Yoneda M, Yasui N, Owaki $\mathrm{H}$ and Ono K: Repair of rabbit articular surfaces with allograft chodnrocytes embedded in collagen gel. J Bone Joint Surg Br 71: 74-80, 1989.

70. Frenkel SR, Toolan B, Menche D, Pitman MI and Pachence JM: Chondrocyte transplantation using a collagen bilayer matrix for cartilage repair. J Bone Joint Surg Br 79: 831-836, 1997.

71. Schuppan D, Schmid M, Somasundaram R, Ackermann R, Ruehl M, Nakamura T and Riecken EO: Collagens in the liver extracellular matrix bind hepatocyte growth factor. Gastroenterology 114: 139-152, 1998.

72. Kauppila S, Stenbäck F, Risteli J, Jukkola A and Risteli L: Aberrant type I and III collagen gene expression in human breast cancer in vivo. J Pathol 186: 262-268, 1998.

73. Minamoto T, Ooi A, Okada Y, Mai M, Nagai Y and Nakanishi I: Desmoplastic reaction of gastric carcinoma: A light- and electron microscopic immunohistochemical analysis using collagen type-specific antibodies. Hum Pathol 19: 815-821, 1988.

74. Bosman FT, de Bruïne A, Flohil C, van der Wurff A, ten Kate J and Dinjens WW: Epithelial-stromal interactions in colon cancer. Int J Dev Biol 37: 203-211, 1993.

75. Dahlman T, Lammerts E, Wik M, Bergström D, Grimelius L, Westermark K, Rubin K and Heldin NE: Fibrosis in undifferentiated (anaplastic) thyroid carcinomas: Evidence for a dual action of tumour cells in collagen type I synthesis. J Pathol 191: 376-386, 2000

76. Pietras K and Ostman A: Hallmarks of cancer: Interactions with the tumor stroma. Exp Cell Res 316: 1324-1331, 2010.

77. Niehans GA, Kratzke RA, Froberg MK, Aeppli DM, Nguyen PL and Geradts J: G1 checkpoint protein and p53 abnormalities occur in most invasive transitional cell carcinomas of the urinary bladder. Br J Cancer 80: 1175-1184, 1999.
78. Mani SA, Guo W, Liao MJ, Eaton EN, Ayyanan A, Zhou AY, Brooks M, Reinhard F, Zhang CC, Shipitsin M, et al: The epithelial-mesenchymal transition generates cells with properties of stem cells. Cell 133: 704-715, 2008

79. Huang R, Wang G, Song Y, Tang Q, You Q, Liu Z, Chen Y, Zhang Q, Li J, Muhammand S, et al: Colorectal cancer stem cell and chemoresistant colorectal cancer cell phenotypes and increased sensitivity to Notch pathway inhibitor. Mol Med Rep 12: 2417-2424, 2015.

80. Alao JP: The regulation of cyclin D1 degradation: Roles in cancer development and the potential for therapeutic invention. Mol Cancer 6: 24, 2007.

81. Ricci-Vitiani L, Lombardi DG, Pilozzi E, Biffoni M, Todaro M, Peschle C and De Maria R: Identification and expansion of human colon-cancer-initiating cells. Nature 445: 111-115, 2007.

82. O'Brien CA, Pollett A, Gallinger S and Dick JE: A human colon cancer cell capable of initiating tumour growth in immunodeficient mice. Nature 445: 106-110, 2007.

83. Gilcrease MZ: Integrin signaling in epithelial cells. Cancer Lett 247: 1-25, 2007.

84. Takada Y, Ye X and Simon S: The integrins. Genome Biol 8: 215 , 2007.

85. Iwatsuki H, Sasaki K, Suda M and Itano C: Vimentin intermediate filament protein as differentiation marker of optic vesicle epithelium in the chick embryo. Acta Histochem 101: 369-382, 1999.

86. Gilles C, Polette M, Zahm JM, Tournier JM, Volders L, Foidart JM and Birembaut P: Vimentin contributes to human mammary epithelial cell migration. J Cell Sci 112: 4615-4625, 1999.

87. Shattil SJ, Kim C and Ginsberg MH: The final steps of integrin activation: The end game. Nat Rev Mol Cell Biol 11: 288-300, 2010.

88. Box C, Rogers SJ, Mendiola M and Eccles SA: Tumour-microenvironmental interactions: Paths to progression and targets for treatment. Semin Cancer Biol 20: 128-138, 2010.

89. Hammoudi A, Song F, Reed KR, Jenkins RE, Meniel VS, Watson AJ, Pritchard DM, Clarke AR and Jenkins JR: Proteomic profiling of a mouse model of acute intestinal Apc deletion leads to identification of potential novel biomarkers of human colorectal cancer (CRC). Biochem Biophys Res Commun 440: 364-370, 2013. 